\title{
Pemberian Insentif dan Tanggung Jawab terhadap Kinerja Karyawan pada PT Yongda Plastics Indonesia
}

\author{
Dedi Sintoso $^{\bowtie 1}$, Heryenzus $^{2}$ \\ 1,2,3 Program Studi Manajemen, Universitas Putera Batam, Indonesia
}

\begin{abstract}
ABSTRAK
Jenis penelitian ini adalah dengan pendekatan kuantitatif. Sampel dalam penelitian ini sebanyak 105 responden yang diambil dengan metode jenuh. Teknik analisis data reliabilitas, uji asumsi klasik, uji koefisien determinasi, dan uji hipotesis. Proses perhitungan dibantu dengan program aplikasi software SPSS 26. Hasil pengujian menunjukkan pemberian insentif berpengaruh positif dan signifikan pada kinerja karyawan, tanggung jawab berpengaruh positif dan signifikan terhadap kinerja karyawan, serta pemberian insentif dan tanggung jawab berpengaruh positif dan signifikan pada kinerja karyawan.
\end{abstract}

Kata-kunci:

Kinerja karyawan, Tanggung jawab, Pemberian insentif

\begin{abstract}
This type of research is a quantitative approach. The sample in this study were 105 respondents who were taken with the saturated method. Data reliability analysis techniques, classical assumption test, determination coefficient test, and hypothesis testing. The calculation process is assisted by the SPSS 26 software application program. The test results show that incentives have a positive and significant effect on employee performance, responsibility has a positive and significant effect on employee performance, and incentives and responsibilities have a positive and significant effect on employee performance.
\end{abstract}

Keywords : Employee performance; Responsible; Incentives Giving

$\triangle$ Corresponding author :

Email Address : dedi_sintoso@upbatam.ac.id

"Received 12, Agustus 2020, Accepted 15, Januari 2021, Published 06, Februari 2021" 


\section{Pendahuluan}

Pertumbuhan perekonomian ialah masalah yang harus dihadapi oleh setiap bangsa agar dapat mempercepat pembangunan di dalam negeri dan tarif kehidupan yang tinggi maka akan banyak perusahaan yang didirikan di dalam negeri yang akan berdampak pada persaingan yang ketat sebab itu setiap negara perlu mengimbangi pertumbuhan penduduk dan lapangan kerja agar tidak banyak terjadinya pengangguran di setiap kota karena Bisnis merupakan unit terintegrasi dengan penekanan utama pada perolehan laba (Ahmad, Mappatompo \& Muslim, 2018; Basalamahet al., 2019; Nasir, 2020)

Kinerja adalah sebuah hasil kerja yang diperoleh dari kemampuan bekerja seseorang baik secara mandiri maupun kelompok yang akan memberikan dampak baik untuk sebuah organisasi. Agar bisa menjadi sebuah contoh untuk semua personil didalam organisasi agar dapat meningkatkan semangat kerja personil yang lain saat diberikan pekerjaan agar dapat menciptakan hasil kerja yang lebih baik lagi (Effendy, A. A., \& Fadhilah, A., 2019).

Ada dua faktor yang dapat menurunkan tingkat kinerja karyawan itu sendiri adalah pemberian insentif dan tanggung jawab dikarenakan setiap perusahaan selalu memiliki visi misi yang kuat untuk dapat mencapai trade record yang bagus dalam dunia perdagangan agar bisa memenuhi jumlah permintaan barang dari konsumen baik didalam negeri maupun luar negeri. (Nisa, F., Suharman, H., \& Hasyir, D., 2020).

Insentif adalah sebuah upah yang perlu diberikan kepada karyawan sesuai dengan kemampuan dan prestasinya jika mencapai sebuah target yang diberikan sesuai dengan perjanjian awal dengan organisasi tersebut agar dapat menimbulkan rasa semangat kerja yang lebih tinggi lagi. Agar dapat menjadi sebuah sarana motivasi yang dapat memberikan dorongan semangat kerja terhadap setiap karyawan yang sedang menjalani tugas yang diberikan oleh perusahaan agar dapat dikerjakan secara optimal. Sebaliknya, karyawan yang tidak mendapatkan pemberian insentif biasanya disebabkan oleh kurangnya semangat kerja dalam pencapaian target yang sudah ditentukan oleh perusahaan. (Yusuf \& Asyhari, 2018) 
Tanggung jawab adalah kewajiban yang harus dikerjakan sesuai aturan yang sudah ditetapkan oleh sebuah perusahaan agar dapat menjaga kepercayaan yang sudah diberikan. Oleh karena itu setiap mendapatkan tugas yang diberikan wajib dijalankan sesuai dengan arahan yang sudah diberikan agar dapat bekerja secara optimal baik di dalam perusahaan maupun diluar perusahaan karyawan yang memiliki potensi dan motivasi yang tinggi akan sering mendapatkan tantangan seperti pemberian tugas yang lebih sulit lagi untuk dapat mencapai sebuah jabatan tinggi yang sangat berpengaruh pada perusahaan tersebut (ProyLokbere, Agus Soepandi Soegoto, 2017)

PT Yongda Plastics Indonesia ialah mitra yang memiliki dibidang industri manufaktur, mitra ini mengolah barang mentah menjadi barang jadi dari bahan plastik seiring berjalannya waktu, timbul permasalahan yang sering muncul didalam perusahaan tersebut antara lain yaitu pemberian insentif yang berbeda-beda kepada karyawannya, yang akan berdampak pada penurunan tanggung jawab dan penurunan kinerja pada setiap karyawan.

\section{Kajian Literatur}

Imbalan adalah pembayaran tetap yang diterima karyawan berdasarkan posisi atau posisi dengan uraian pekerjaan yang dikerjakan. Memprioritaskan gaji dan upah, karyawan bisa bekerja sesuai (setidaknya). Dalam peningkata kinerja, mitra secara langsung menghubungkan kinerja dengan imbalan yang didapat orang dalam bentuk imbalan. Selain upah dan upah, Sistem ini merupakan bentuk lain dari gaji langsung, yaitu gaji tetap yang disebut sistem gaji berbasis kinerja (performance plan compensation). (Rifa, M. N., Sukidjo, S., 2019).

Insentif juga memiliki efek psikologis karyawan karena mereka merasa upaya mereka diperhatikan dan mereka dihargai berdasarkan kinerja mereka. Insentif dapat diberikan kepada karyawan dengan berbagai cara seperti pembayaran bonus, bagi hasil, insentif saham, Pensiun insentif, insentif dan hadiah Liburan (Khan, Abbas, \& Zaki, 2017).

Menurut (Sinambela, 2017:245) terdapat beberapa contoh pemberian insentif ialah : 
1) Sederhana, Aturan sistem insentif harus ringkas dan mudah dipahami

2) Spesifik, pegawai diharapkan tahu persis apa yang harus mereka perbuat

3) Dapat dicapai, seluruh pegawai memiliki peluang yang wajar untuk memperoleh penghasilan

4) Dapat diukur, dapat dilaksanakan pengukuran dengan tujuan untuk menentukan rencana insentif

Menurut (N. Yusuf, 2018) Tanggung jawab mengacu pada kemampuan untuk menyelesaikan pekerjaan yang ditugaskan tepat waktu dan benar, serta mengambil risiko untuk mengambil keputusan. Menurut (Akila, 2020) Harus memikul tanggung jawab dalam arti kewajiban yang harus dilaksanakan seluruh orang. Tanggung jawab terkait dengan kualitas moral, hukum dan tanggung jawab moral. Menurut (Rifmanesi, Elfianto Yusuf, 2019) Tanggung jawab adalah kewajiban untuk melaksanakan semua tugas yang diberikan kepadanya sesuai dengan kewenangan yang telah diperoleh atau dimilikinya. Tanggung jawab muncul dari hubungan antara atasan dan bawahan, atasan mendelegasikan otorisasi kerja kepada bawahan. Berdasarkan (Hasibuan, 2014:70) Tanggung jawab merupakan kewajiban untuk melaksanakan semua tugas atau tanggung jawab yang diberikan kepada mereka karena wewenang yang telah mereka peroleh atau miliki. Penjelasan (N. Yusuf, 2018) mengenai tanggung jawab indikator adalah seperti berikut :

1) Kepemilikan sikap dan kesadaran yang tinggi, serta menampilkan tanggung jawab yang besar terhadap pekerjaan.

2) Mampu menyelesaikan pekerjaan dengan benar tepat waktu.

3) Berani mengambil resiko dalam pengambilan keputusan.

4) Kerja keras dan dedikasi.

Menurut (Heryenzus, 2017) Kinerja ialah berupa konsep atau singkatan berdasarkan ilmu gerak pada energy kerja yang bahasa inggrisnya adalah performance. Arti performance itu sendiri bisa diartikan dalam bahsa Indonesia yang dikenal kinerja. Menurut (Farizki \& Wahyuati, 2017) Prestasi kerja karyawan (job performance) mengacu pada kualitas dan 
kuantitas pekerjaan yang dilakukan oleh setiap pegawai dengan tugas yang diberikan kepadanya.

Menurut (Irawati \& Carollina, 2017) Kinerja adalah kualitas dan kuantitas hasil kerja yang diperoleh seorang karyawan saat melaksanakan tugas sesuai dengan tugas yang diberikan kepadanya. Menurut (Sunaryo \& Nasrul, 2018) Kinerja adalah gambaran mengenai tingkat pencapaian pelaksanaan suatu kegiatan/program/kebijakan dalam mewujudkan sasaran, tujuan, misi dan visi organisasi yang tertuang dalam strategic planning. Menurut (dewi, bagia, 2018) Kinerja karyawan merupakan hasil kerja karyawan dalam kurun waktu tertentu.

Gambar 1. Kerangka Berpikir

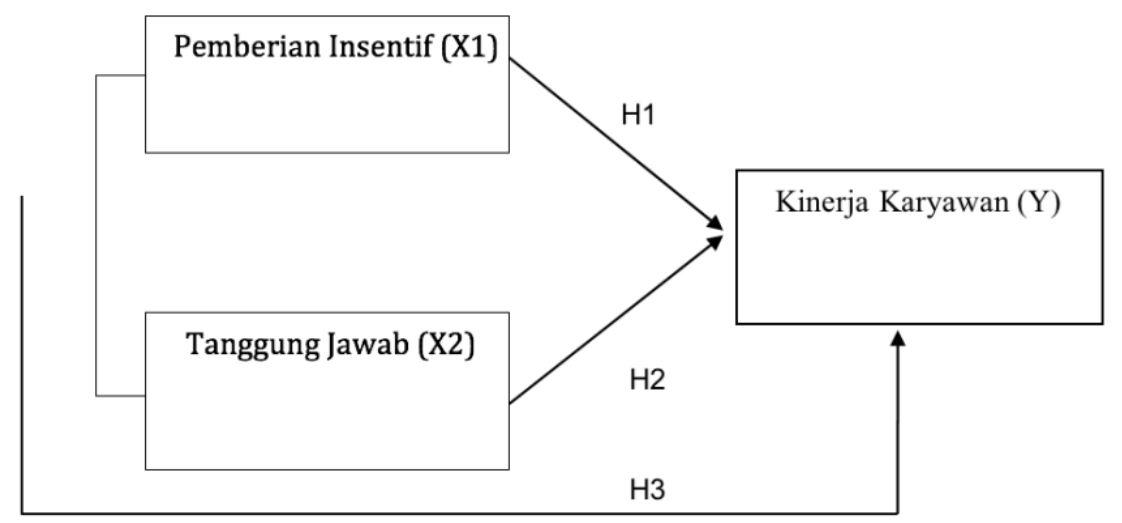

H1: Pemberian insentif berpengaruh positif dan signifikan terhadap kinerja karyawan PT. Yongda Plastics Indonesia.

H2: Tanggung jawab berpengaruh positif dan signifikan terhadap kinerja karyawan PT. Yongda Plastics Indonesia.

H3: Pemberian insentif dan Tanggung jawab secara simultan berpengaruh positif dan signifikat terhadap kinerja karyawan PT. Yongda Plastics Indonesia.

\section{Metode Penelitian}

Desain penelitian adalah rencana struktur penelitian yang mengarahkan proses dan hasil penelitian sedapat mungkin menjadi valid, objektif, efisien, dan efektif. (Uma Sekaran, 2017:152) Metode penelitian pada dasarnya adalah metode ilmiah untuk memperoleh 
data untuk tujuan dan kegunaan tertentu. (Sugiyono, 2015:2) Variabel penelitian adalah segala bentuk yang ditentukan oleh peneliti untuk memperoleh informasi tentangnya dan kemudian menarik kesimpulan. (Riyanto, 2020) Variabel dalam penelitian ini memakai dua jenis variabel, antara lain (Ahmadi, 2016:118) (1) Variabel independen (X) adalah variabel yang mempengaruhi atau menyebabkan perubahan atau terjadinya variabel terikat (dependent variable) (2) Variabel Dependen (Y) merupakan faktor utama untuk menjelaskan atau memprediksi dan mempengaruhi, atau hasil dari variabel lain. Populasi dalam penelitian ini pendasaran data yang disediakan oleh Bagian Human Resources Department (HRD) PT. Di PT. Karyawan Yongda Plastics Indonesia Batam adalah Yongda Plastics Indonesia, sebanyak 105 orang. Dalam penelitian ini dikarenakan total karyawan PT. Yongda Plastics Indonesia di Kota Batam memiliki sebanyak 105 karyawan, sehingga peneliti menggunakan teknik sampling jenuh untuk menentukan jumlah sampel dan sampel semua populasi.

\section{Hasil Penelitian}

Standar kepastian dalam pengujian reliabilitas memanfaatkan teknologi Alpha Cronbach. Jika memiliki faktor reliabilitas atau alpha melebihi dari 0,6, dapat dipastikan. Cronbach's Alpha bernilai tidak lebih besar dari 0,6. pada tabel sebagai berikut:

Tabel 1. Hasil Uji Reliabilitas

\begin{tabular}{llll}
\hline Variabel & Cronbach's Alpha & Kriteria & Keterangan \\
\hline Pemberian Insentif & 0,887 & 0,6 & Reliabel \\
(X1) & 0,879 & 0,6 & Reliabel \\
Tanggung Jawab (X2) & 0,879 & 0,6 & Reliabel \\
Kinerja Karyawan (Y) & & &
\end{tabular}

Sumber : Data Penelitian (2020).

Memanfaatkan studi ini, para peneliti melakukan analisis grafik dengan menggunakan plot histogram dan Normal P- P Plot of Regression Standardized Residual dan tes ndonesia melalui uji Kolmogrov Smirnov (KS), pada gambar sebagai berikut : 
Gambar 2. Uji Normalitas Kurva Histogram

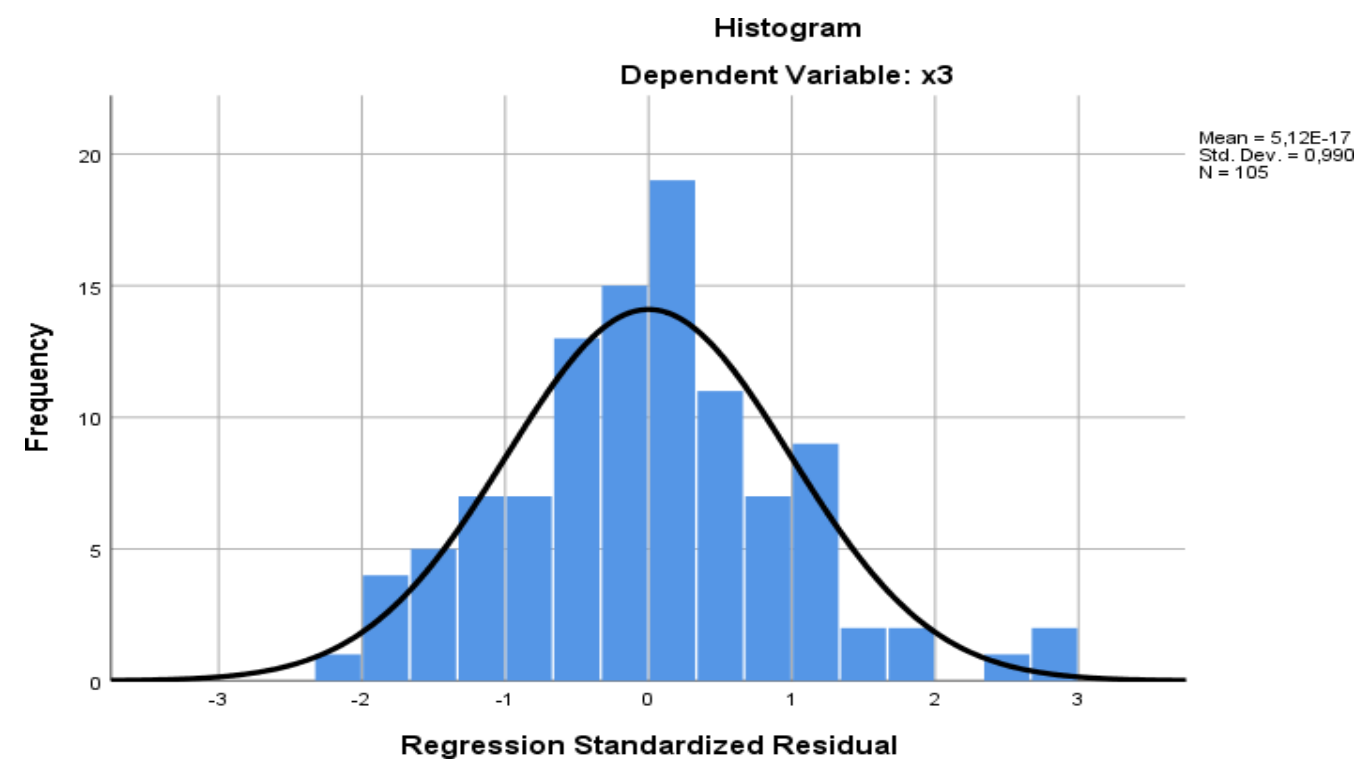

Sumber : Data Penelitian (2020)

Tabel 2. Hasil Uji Koefisien Determinasi

\begin{tabular}{lcccccc}
\hline Model & \multirow{2}{*}{$\mathrm{R}$} & $\mathrm{R}$ & Adjust \\
Square & $\mathrm{R}$ & $\begin{array}{c}\text { Std. } \\
\text { Estimate }\end{array}$ & $\begin{array}{c}\text { Error of the } \\
\text { Estimate }\end{array}$ \\
\hline 1 &, $632^{\mathrm{a}}$ &, 399 &, 387 & 2,681 & \\
\hline
\end{tabular}

Sumber : Data Penelitian (2020)

Dapat diperhatikan dari tabel di atas bahwa nilai (R2) dari hasil uji koefisien determinasi adalah 0,399. Ini berarti bahwa dalam model regresi ini, persentase variabel pemberian insentif dan tanggung jawab adalah 39,9\%, selain itu perolehan hasil variabel lain (hingga $60,1 \%$ ) terpengaruhi oleh faktor-faktor lain yang mempengaruhi kinerja karyawan PT Yongda Plastics ndonesia di Batam

Tabel 3. Hasil Uji F

\begin{tabular}{lllllll}
\hline Model & & $\begin{array}{l}\text { Sum of } \\
\text { Square }\end{array}$ & df & $\begin{array}{c}\text { Mean } \\
\text { Square }\end{array}$ & F & Sig. \\
\hline \multirow{2}{*}{1} & Regression & 486,595 & 2 & 243,480 & 33,881 &, $000^{b}$ \\
& & & & & & \\
& Residual & 733,003 & 102 & 7,186 & & \\
\hline
\end{tabular}

Sumber : Data Penelitian (2020)

Menurut Tabel di atas, variabel "pemberian insentif" dan "tanggung jawab" secara simultan mempunyai pengaruh positif dan signifikan terhadap kinerja karyawan. Nilai $\mathrm{F}$ 
yang dihitung positif pada 33,881, dan nilai signifikan 0,000 tidak lebih besar dari angka $\alpha 0,05$. Sehingga bisa dipastikan diterimanya hipotesis ketiga.

\section{Pembahasan}

Untuk mengetahui pengaruh masing-masing variabel independen terhadap variabel dependen, hasil yang diperoleh pada Tabel 3 menunjukkan bahwa variabel yang diberikan insentif memiliki pengaruh positif sebesar 3.137, dan signifikansi 0,003 tidak melebihi nilai $\alpha 0,05$. Oleh karena itu dapat dipastikan hipotesis pertama dari penelitian ini menunjukkan bahwa variabel insentif berpengaruh signifikan terhadap kinerja karyawan PT Yongda Plastics Indonesia. Koefisien regresi pemberian insentif variabel positif berarti bahwa meningginya angka pemberian insentif, meninggi juga angka kinerja karyawan. Pemberian insentif dapat meningkatkan kinerja karyawan PT Yongda Plastics Indonesia.

Berdasarkan hasil yang digunakan untuk mengetahui pengaruh masing-masing variabel bebas terhadap variabel terikat, hasil uji-t pada Tabel 3 menunjukkan bahwa pengaruh positif variabel yang bertanggung jawab sebesar 2,513 dan signifikansi 0,018 lebih kecil dari $\alpha 0,05$. Sehingga bisa dikatakan diterimanya hipotesis kedua, yang menunjukkan bahwa variabel tanggung jawab PT Yongda Plastics Indonesia di Batam mempunyai pengaruh yang signifikan terhadap kinerja karyawan. Variabel koefisien tanggung jawab memiliki nilai positif, yang mempunyai arti bahwa meningginya angka tanggung jawab, semakin tinggi pula angka kinerja karyawan. Dampak Tanggung Jawab menyatakan hasil yang positif dan signifikan dalam kinerja karyawan terhadap Kinerja Karyawan PT Yongda Plastics Indonesia. Hasil penelitian yang selalu menguji pengaruh partisipasi anggaran terhadap kinerja manajerial juga mendukung hal tersebut (Ermawati, 2017; Jatmiko, 2017; Giusti et al., 2018; Pratiwi, 2019; Andison \& Augistine, 2017; Marlina, 2019). Dari penelitian ini diketahui bahwa partisipasi dalam penyusunan anggaran memiliki pengaruh yang signifikan terhadap kinerja manajemen. Oleh karena itu dapat dikatakan bahwa penelitian ini mendukung hasil penelitian yang dilakukan oleh peneliti sebelumnya.

Tanggung Jawab yang dimaksud adalah kegiatan perusahaan yang diserahkan kepada karyawan baik secara langsung dan tidak langsung besarnya tanggung jawab yang 
dikerahkan kepada karyawan maka bisa menaikkan Kinerja Karyawan PT Yongda Plastics Indonesia.

Menurut hasil uji-F yang diteliti demi menentukan efek simultan variabel pemberian insentif dan tanggung jawab terhadap kinerja karyawan, hasil uji-F yang diperoleh dalam menunjukkan bahwa variabel pemberian insentif dan tanggung jawab secara simultan memiliki dampak positif senilai 33.881, dan secara signifikan 0,00 tidak lebih besar dari angka $\alpha 0,05$. Temuan penelitian ini berasal dari penelitian sebelumnya (Lamato, 2017; Adhiputra, 2019; Laiya \& Pondaag, 2018; Komara, 2017). Maka bisa dikatakan bahwa hipotesis ketiga penelitian ini menyatakan bahwa variabel pemberian insentif dan tanggung jawab mempunyai pengaruh signifikan terhadap kinerja karyawan PT Yongda Plastics Indonesia.

\section{Kesimpulan}

PT Yongda Plastics Indonesia memprioritaskan pemberian insentif dan memberlakukan metode pemberian yang adil dan sistem manajemen yang bagus. Ini dapat mencapai kinerja karyawan yang diharapkan perusahaan. Diharapkan kepada peneliti selanjutnya supaya bisa mengerjakan penelitian dan pengembangan yang lebih intensif pada pemberian insentif dan tanggung jawab terhadap kinerja karyawan yang bisa membuat hasil yang diperoleh lebih sempurna dan lebih bermanfaat.

\section{Referensi :}

Adhiputra, M. W. (2019). Analisis Penerapan Tqm Terhadap Kinerja Manajerial Pada Rumah Sakit Umum Di Denpasar. JIA (Jurnal Ilmiah Akuntansi), 3(1). http://dx.doi.org/10.23887/ jia.v3i1. z16628

Ahmad, H., Mappatompo, A., \& Muslim, M. (2018). Capital Ownership Structure And Decision On Fi-financial Market Reaction And Corporate Value. International Journal of Innovative Science and Re-search Technology, 3(9), 395-406. https://doi.org/10.1016/i.jinteco.2013.10.007

Andison, A., \& Augustine, Y. (2017). Partisipasi Anggaran, Kepuasan Kerja, dan Kinerja Manajerial: Studi Pada Bisnis Keluarga Pempek di Kota Palembang. Esensi: Jurnal Bisnis dan Manajemen, 7(1), 73-82

Basalamah, J., Pramukti, A., \& Basalamah, A. (2019). Kemampuan, Komitmen Dan Sarana Prasarana Terhadap Kinerja Pegawai Rumah Sakit. CESJ: Center Of Economic Students Journal, 2(2), 153-164. 
Effendy, A. A., \& Fadhilah, A. (2019). Pengaruh Insentif Dan Motivasi Terhadap Kinerja Karyawan Pada Pt. Calibramed Jakarta Selatan. Jimf (Jurnal Ilmiah Manajemen Forkamma), 1(3), 85-96. https://doi.org/10.32493/frkm.v1i3.2551

Ermawati, N. (2017). Pengaruh Partisipasi Anggaran terhadap Kinerja Manajerial dengan Motivasi Kerja sebagai Variabel Pemoderasi (Studi Kasus SKPD Kabupaten Pati). JurnalAkuntansi Indonesia, 6(2), 141-156

Giusti, G., Kustono, A. S., \& Effendi, R. (2018). Pengaruh Partisipasi Anggaran Terhadap Kinerja Manajerial dengan Komitmen Organisasi dan Motivasi Sebagai Variabel Intervening. e-Journal Ekonomi Bisnis dan Akuntansi, 5(2), 121-128.

Irawati, R., \& Carollina, D. A. (2017). Analisis Pengaruh Beban Kerja Terhadap Kinerja Karyawan Operator Pada Pt Giken Precision Indonesia. Inovbiz: Jurnal Inovasi Bisnis, 5(1), 51. https://doi.org/10.35314/inovbiz.v5i1.171

Khan, A. A., Abbas, N., \& Zaki, K. A. (2017). Effect of incentives based two factor theory on employee performance in telecom sector of Pakistan. The Nucleus, 54(3), 173-180.

Lamato, B. R., Jan, A. B. H., \& Karuntu, M. M. (2017). Analisis Total Quality Management (TQM) Terhadap Kinerja Manajerial Pada PT. Asegar Murni Jaya Desa Tumaluntung KAB. Minahasa Utara. Jurnal EMBA: Jurnal Riset Ekonomi, Manajemen, Bisnis dan Akuntansi, 5(2).

Laiya, R. A. R., Jan, A. B. H., \& Pondaag, J. J. (2018). Pengaruh Total Quality Management (Tqm) Terhadap Kinerja Manajerial Pada Pt. Bank Mandiri (Persero) Tbk Area Manado. Jurnal EMBA: Jurnal Riset Ekonomi, Manajemen, Bisnis dan Akuntansi, 6(4). https:// doi.org/10.35794/emba.v6i4.21047

Marlina, E., \& Zega, B. L. (2019). AnalisisDeterminasi Kinerja Manajerial: Studi Empiris Pada Rumah Sakit Umum Daerah Propinsi Riau. Muhammadiyah Riau Accounting and Business Journal, 1(1), 1-9

Nasir, M. (2020). Etika dan Komunikasi dalam Bisnis: Tinjauan Al-Qur'an, Filsafat dan Teoritis. CV. Social Politic Genius (SIGn).

Nisa, F., Suharman, H., \& Hasyir, D. A. (2020). Ketidakpastian Permintaan Pelanggan Sebagai Pemicu Manajemen Persediaan Dengan Pendekatan Analisis FSN. Syntax Literate; Jurnal Ilmiah Indonesia, 5(4), 56-63. http://dx.doi.org/10.36418/syntaxliterate.v5i4.1067

Pratiwi, W., \& Kartika, A. A. (2019). Pengaruh Akuntansi Pertanggungjawaban, Komitmen Organisasi, Dan Partisipasi Anggaran Terhadap Kinerja Manajerial. Wahana: Jurnal Ekonomi, Manajemen dan Akuntansi, 22(1), 50-60

Riyanto, S., \& Hatmawan, A. A. (2020). Metode Riset Penelitian Kuantitatif Penelitian Di Bidang Manajemen, Teknik, Pendidikan Dan Eksperimen. Deepublish.

Rifa, M. N., Sukidjo, S., \& Efendi, R. (2019). The Performance of Employees Influenced by Leadership Styles and Compensation. International Journal of Multicultural and Multireligious Understanding, 6(6), 581-587. http://dx.doi.org/10.18415/ijmmu. v6i6.1243

Sugiyono, S. (2010). Metode penelitian kuantitatif dan kualitatif dan R\&D.

Wiryana, L., \& Augustine, Y. (2014). Pengaruh Karakteristik Informasi Sistem Akuntansi Manajemen terhadap Kinerja Manajerial dengan Variabel Moderasi Strategi Bisnis, 
Perceived Environmental Uncertainty (Peu), Ketidakpastian Tugas dan Desentralisasi. Jurnal Magister Akuntansi Trisakti, 1(2), 155-180. 